\title{
O KANAIMÉ EM TERRITÓRIO WAPICHANA: REGIÃO AMAZÔNICA ENTRE O BRASIL E A GUIANA INGLESA
}

\section{KANAIMÉ IN WAPISHAN TERRITORY: AMAZON REGION BETWEEN BRAZIL AND ENGLISH GUYANA}

\begin{abstract}
Ananda Machado ${ }^{1}$, Jama Peres Pereira ${ }^{2}$
RESUMO: O artigo é o resultado parcial de uma pesquisa que tem buscado biografar vidas de indígenas Wapichana da fronteira entre o Brasil e a República Cooperativa da GuianaRegião Amazônica. As narrativas sobre o Kanaimé (ser que representa o mau) são recorrentes nessa região e fazem parte da biografia do indígena Wapichana entrevistado. Usamos a metodologia da história oral e assim essa biografia, as práticas do Kanaimé e as narrativas relacionadas à sua origem e morte são vetores para discussões teóricas sobre a figura do narrador e como suas experiências e narrativas orais permanecem na memória, fazendo parte da vida e da identidade cultural dos Wapichana e de outros povos indígenas que vivem entre o Brasil e a Guiana Inglesa.
\end{abstract}

PALAVRAS-CHAVE: narrativas orais; Wapichana; Kanaimé

ABSTRACT: The article is the partial result of a research that has sought to biograph the lives of indigenous Wapishana on the border between Brazil and the Cooperative Republic of Guyana - Amazon Region. The narratives about Kanaime (being that represents the bad) are recurrent in this region and are part of the biography of the indigenous Wapishana interviewed. We use the methodology of oral history and so this biography, the practices of Kanaime and the narratives related to its origin and death are vectors for theoretical discussions about the figure of the narrator and how his experiences and oral narratives remain in memory, being part of life and cultural identity of Wapishana and other indigenous peoples living between Brazil and English Guiana

KEYWORDS: oral narratives, Wapishana, Kanaime

\section{Introdução}

\footnotetext{
${ }^{1}$ Doutora em História Social-UFRJ, com Pós-Doutorado em Estudos de Literatura-UFF. Professora no PPG em Letras da UFRR e no curso Gestão Territorial Indígena, Instituto Insikiran de Formação Superior Indígena UFRR.

${ }^{2}$ Indígena Wapichana formada em Gestão Territorial Indígena com ênfase em Patrimônio Indígena-UFRR; Mestranda Letras-Literatura pela UFRR. Professora de língua Wapichana em cursos de extensão- UFRR.
} 
$\mathrm{Na}$ história de vida aqui exposta, narrada pelo indígena Wapichana Muхитихи, o Kanaimé aparece de forma marcante. Tanto o entrevistado como os Kanaimé vivem para além da fronteira Brasil-Guiana, relacionando medo, vida e morte. O Kanaimé, essa figura enigmática, é recorrente nas narrativas orais da região e elas foram escolhidas para serem lidas, documentadas e analisadas neste artigo.

O Kanaimé é muito presente na vida dos povos indígenas de Roraima, principalmente relacionado a situações de medo, violência e morte. Além do uso da biografia do Wapichana Михитихи, realizamos também aqui uma revisão bibliográfica sobre o tema Kanaimé, principalmente a partir dos trabalhos etnográficos de Koch-Grümberg (1984), Farage (1997), Whitehead (2002), que exploram aspectos desse processo de violência cultural pelo Kanaimé. Construímos assim um estudo comparativo, observando como os Wapichana o entendem e como outros autores compreenderam essas práticas e histórias.

A pesquisa de campo foi realizada na sede do município Bonfim ${ }^{3}$, local onde ouvimos a história de vida do indígena Wapichana Михитихи. Sua biografia revela a prática de transitar pessoas e conhecimentos entre o Brasil e a República Cooperativa da Guiana. O indígena entrevistado é poliglota e falou durante as entrevistas nas línguas Wapichana, inglesa e portuguesa.

Os indígenas Wapichana falam uma língua da família Aruak (RODRIGUES, 1986) e vivem entre os povos da grande família Caribe: Macuxi, Waiwai, Taurepang, Patamona e Ingarikó. Portanto, as narrativas de Kanaimé fazem parte da vida desses povos indígenas que vivem nesse território amazônico.

No Estado de Roraima, a população indígena é constituída por 55.922 indivíduos, conforme dados extraídos pelo IBGE (2010). Desse quantitativo, segundo estimativas da SIASI/SESAI (2014 apud ISA, 2018), o povo Wapichana se apresenta no quadro roraimense com 9.441 indígenas. Na Guiana, Farage (1997), aponta a população Wapichana em torno de 6.000 indivíduos entre aldeados e citadinos.

A demarcação das terras, a situação econômica brasileira, a diminuição da violência dos fazendeiros e a piora na situação econômica da Guiana impulsionou consideravelmente o fluxo de indígenas no sentido Guiana-Brasil a partir da década de 1980 (LIMA, 2013, p.102).

Escrevemos aqui parte da biografia do indígena Wapichana Михитихи, tomando como fundamento metodológico as ideias de Bourdieu, para quem "falar de história de vida é

\footnotetext{
${ }^{3}$ Bonfim tem uma população de 3.711 pessoas, com aproximadamente $40 \%$ sendo indígenas das etnias Macuxi e Wapichana (IBGE, 2010).
} 
pelo menos pressupor e isso não é pouco- que a vida é uma história; uma vida é inseparavelmente o conjunto de acontecimentos de uma experiência individual concebida como uma história e o relato dessa história” (BOURDIEU in AMADO; FERREIRA, 2006, p. 183). Fundamentamos nossas práticas de entrevista a partir de estudos de história oral por Alberti (1989; 2004) e Fraser (1993). E para pensar o papel do narrador citamos Benjamin (1994).

Por uma série de motivos, dentre eles a entrada: da energia elétrica 24 horas, da internet, da televisão, das escolas e das igrejas nas comunidades indígenas, as práticas de narrar em algumas comunidades vêm sofrendo um processo de esquecimento. Para refletir sobre essa questão, nos apoiamos no que Walter Benjamin (1994) reforça: que o narrador busca assimilar a importância daquilo que nem sempre presenciou, mas que teve acesso através de narrativas que lhe foram transmitidas. Abrimos assim aqui também um espaço para dialogar sobre o narrador, sua experiência e prática de narrar. E na sequência faremos uma análise das narrativas do indígena Михитихи, entrevistado, falando sobre os medos, as práticas e as mortes do Kanaimé e os pajés dentro da cultura Wapichana.

\section{História oral, o narrador e sua experiência}

Para realizar as entrevistas, seguimos os procedimentos da história oral, metodologia de pesquisa que usa entrevistas gravadas com pessoas que podem testemunhar sobre acontecimentos, modos de vida ou outros aspectos da história contemporânea. De acordo com o Estatuto da Associação Brasileira de História Oral, por História Oral entende-se o trabalho de pesquisa que utiliza fontes orais em diferentes modalidades, independente da área de conhecimento na qual essa metodologia venha a ser utilizada (ALBERTI, 1989).

Conforme preconiza o Manual de História Oral de Verena Alberti (2004), em uma entrevista, alguns princípios devem ser mantidos e considerados. Dessa forma, as narrativas precisam ter, quando da sua execução e processamento dos dados: entrevistador e entrevistado, transcrição fidedigna, conferência de fidelidade e copidesque.

A relação entre entrevistador e entrevistado deve ser de confiança e respeito. Cabe ao entrevistador buscar ao máximo seguir um roteiro, porém com a flexibilidade que o andar da entrevista exige e com o tempo e ritmo do entrevistado, ou seja: o entrevistador precisa ser um bom ouvinte (ALBERTI, 2004). 
Falar de Kanaimé, como fizemos aqui, ainda mais quando se trata de agressões vividas na própria família do entrevistado, é assunto sensível e por isso a confiança entre entrevistador e entrevistado precisou ser ainda maior.

Segundo Fraser, a narrativa oral oferece ao pesquisador um tecido cuja forma e estampa estariam diretamente permeadas pela mediação entre narrador e ouvinte, pela bagagem cultural do narrador, por elementos psicológicos - relativos a personalidades, à comportamento, afetividade, pelo grau de identificação com seu grupo social, pelo domínio de linguagem (FRASER,1993, p. 134).

Ao contar sua história, o narrador lança mão de formas culturalmente reconhecidas para alcançar o seu intento de comunicar certo conteúdo, que é condicionado pelas demandas de indagações feitas pelo pesquisador/ouvinte e pelas escolhas feitas pelo narrador (FRASER,1993).

A História oral estabelece assim procedimentos - tais como os tipos de pesquisa, entrevistas e suas devidas implicações a partir das transcrições dos depoimentos, assim como pela análise, definidos dessa maneira por Alberti:

[...] a história oral apenas pode ser empregada em pesquisas sobre temas contemporâneos, ocorridos em um passado não muito remoto, isto é, que a memória dos seres humanos alcance, para que se possa entrevistar pessoas que dele participaram, seja como atores, seja como testemunhas. É claro que, com o passar do tempo, as entrevistas assim produzidas poderão servir de fontes de consulta para pesquisas sobre temas não contemporâneos (ALBERTI,1989, p.4).

Para este artigo, além de entrevistas realizadas, nos apropriamos de trabalhos realizados por outros pesquisadores com esses indígenas que vivem na fronteira entre Brasil e Guiana Inglesa. Essa forma de abordagem funciona como ferramenta que permite uma maior interação entre pesquisador e entrevistado, unindo assim a parte teórica à prática, o que refletirá no resultado das pesquisas (ALBERTI,1989).

\footnotetext{
Um método de pesquisa (histórica, antropológica, sociológica) que privilegia a realização de entrevistas com pessoas que participaram de, ou testemunharam acontecimentos, conjunturas, visões de mundo, como forma de se aproximar do objeto de estudo. Trata-se de estudar acontecimentos históricos, instituições, grupos sociais, categorias profissionais, movimentos, etc (ALBERTI, 1989, p. 5).
}

Nesta pesquisa, realizada na área de Literatura e Línguas Indígenas, praticamos a história oral, incluindo a complexidade da tradução, uma vez que o entrevistado fala três línguas: Wapichana, Inglês e Português. Este é mais um aspecto importante que evidencia a riqueza do contexto aqui analisado. Para o entrevistado, a língua Wapichana é a língua da família, da ancestralidade, da origem das histórias; o inglês é a segunda língua, aprendida na 
escola do país de nascimento do entrevistado, que foi colonizado pela Inglaterra. O português, após a migração, também foi aprendido por Михитихи na escola e serviu para ele encontrar trabalho no Brasil.

Nesse artigo, transcrevemos as entrevistas ora na língua Wapichana, incluída nas notas de rodapé e traduzida nas citações diretas deste texto, ora em português, quando o entrevistado respondeu diretamente nossas perguntas na língua portuguesa.

Walter Benjamin, em seu ensaio Experiência e Pobreza (1933), aborda como se deu o retraimento da transmissão de experiências - através de provérbios, narrativas e histórias. Ele reforça que o ato de narrar é fruto da experiência acumulada e também uma forma de estabelecer intercâmbios e reavivar a memória que fornece um suporte dessas lembranças (BENJAMIN, 1994).

Benjamin questiona que com a perda do vínculo entre os indivíduos e o patrimônio cultural a partir das experiências, a humanidade como um todo ficará mais pobre não só de experiências transmissíveis, mas também culturalmente. Esse contexto leva a um novo conceito de barbárie - o da pobreza de experiências transmissíveis. Segundo o autor, "a experiência que passa de pessoa a pessoa é a fonte a que recorreram todos os narradores" (BENJAMIN, 1994, p. 198).

Embora a prática de narrar não tenha desaparecido por completo, mesmo nas comunidades indígenas, ela vem sofrendo um processo de esvaziamento. Há uma assimetria estabelecida entre o Estado brasileiro e os povos indígenas que vem sendo um dos elementos responsáveis por esse processo. Walter Benjamin, há mais de oito décadas discutiu este tema e já sinalizava uma crise:

Está em vias de extinção. São cada vez mais raras as pessoas que sabem narrar devidamente. Quando se pede num grupo que alguém narre alguma coisa, o embaraço se generaliza. É como se estivéssemos privados de uma faculdade que nos parecia segura e inalienável: a faculdade de intercambiar experiências (BENJAMIN, 1994, p.197).

Assim, a fluência e a performance narrativa ficam relegadas a poucos, que ainda lutam para ligar o passado ao presente em uma relação dialógica que tenta perpetuar histórias através da oralidade. E sobre o narrador, Benjamin afirma ainda:

O narrador assimila à sua substância mais íntima aquilo que sabe por ouvir dizer, seu dom é poder contar sua vida; sua dignidade é contá-la inteira. O narrador é o homem que poderia deixar a luz tênue da sua narração consumir completamente a mecha de sua vida. Daí atmosfera incomparável que circunda o narrador (BENJAMIN, 1994, p. 221). 
Sendo a narração uma prática de reconstruir as experiências vividas, vivenciadas ou transmitidas, ela busca, também, recompor a memória e pensar a respeito do valor das narrativas imemoriais e da ancestralidade. O pensamento do escritor indígena Daniel Munduruku também segue na direção dessas ideias de Benjamin, quando afirmou:

[...] somos a continuação de um fío que nasceu há muito tempo atrás [...] Vindo de outros lugares [...] iniciados por outras pessoas [...] Completado, remendado, costurado e [...] continuado por nós. De forma mais simples, poderíamos dizer que temos uma ancestralidade, um passado, uma tradição que precisa ser continuada, bricolada todo dia (MUNDURUKU, 2002, p.41).

Ao discutir o narrador, o intercambiar experiências, memórias e a arte de narrar, percebemos a importância das narrativas a partir do tempo em que se estabelecem os acontecimentos, e da difusão desse conhecimento através da oralidade que ajuda a desfazer uma ideia pré-concebida de que as narrativas são frutos apenas de um passado longínquo, portanto, apenas ficcionais, fora do tempo histórico e testemunhal em que vivemos. Muitas das narrativas orais fazem parte da vida das pessoas na atualidade.

Finalizamos aqui essa breve discussão teórica e apresentamos o entrevistado para este artigo: o indígena Михитихи é um grande narrador Wapichana, conhecido entre seu povo pelas suas habilidades com a palavra. Ele compartilha histórias antigas que vieram de seus ancestrais e também as da sua relação com outros povos e experiências de vida. Mas antes das suas histórias, na sequência deste texto, analisaremos narrativas que giram em torno do tema Kanaimé e pajé.

\section{O Kanaimé e o Pajé}

Para muitos indígenas, o Kanaimé é considerado como bandido, assassino, sinônimo de maldade, ou é visto ainda como o mal propriamente dito. No imaginário do povo Wapichana o Kanaimé é uma das entidades mais perigosas, causadora de incômodos físicos e morte, o que ficou evidente na narrativa do nosso entrevistado.

Alguns indígenas associam o Kanaimé a sentimentos vingativos, negativos e a poderes malignos dos chanaminayzu $u^{4}$ E nos casos desse tipo de ataque, não há outra defesa contra os males do Kanaimé, do que os poderes dos marynau ${ }^{5}$. Como em tudo na vida, há os dois lados

\footnotetext{
${ }^{4}$ Os Wapichana chamam de chanaminayzu os pajés que fazem o mal.

${ }^{5}$ Pajé/xamã detentor de conhecimentos espirituais. Chefe espiritual Wapichana que guarda segredos invioláveis, indivíduo responsável pela condução do ritual, e a quem se atribui a autoridade de invocar e controlar espíritos, o que confere à sua ação encantatória poderes oraculares e curativos (CARVALHO, 2016).
} 
e os mesmos conhecimentos e poderes podem ser usados em uma direção ou em outra. Assim, enquanto os chanaminayzu trabalham para vinganças, violências e mortes, o marynau cura e protege.

Após a chegada das igrejas, os Wapichana passaram a comparar os Kanaimé ao demônio, simbolizando tudo que causa medo. As práticas de Kanaimé foram associadas aos aspectos menos controláveis da existência que sucumbem a instintos violentos reprimidos.

Robert Hermann Schomburgk, naturalista e explorador britânico, registrou sua interpretação do significado do Kanaima ${ }^{6}$.

\begin{abstract}
$\mathrm{Na}$ demonologia dos macuxis, akawais, wapixanas e arekunas, este Kanaima desempenha um papel bastante peculiar. Parece ser não apenas a personificação do desejo de vingança do homem, mas também o autor e a origem de todo mal, no entanto sem se converter num sujeito individual e específico- em poucas palavras, um Proteu sem forma definida ou concepção fixa. Eles nunca nos revelam o que é ou quem é Kanaima, mas todas as mortes, para eles, ocorrem por sua causa, sua culpa (1931, v. 1, p. 288).
\end{abstract}

Koch-Grümberg ouviu de alguns indígenas que: "Kanaimé não é um homem", afirmaram que era um: "inimigo oculto, algo inexplicável, algo sinistro". O etnólogo considerou que: “o conceito de Kanaimé desempenha um papel muito importante na vida desses índios" (2006, p.70). Observou ainda que "tribos inteiras podem ser Kanaimés, tribos vizinhas e hostis, tribos cuja inimizade anterior se converteu em amizade desconfiada são aberta ou secretamente chamadas de Kanaimé. Uma tribo sempre usa o termo para denominar outra tribo" (KOCH-GRÜMBERG, 1984, v. 3, p. 186).

Para Koch-Grümberg, alemão que viajou pelo território hoje chamado Roraima,

O Kanaimé pode ser determinada pessoa. O vingador de uma ofensa, executor da vingança, de um assassinato, que muitas vezes persegue sua vítima durante anos até conseguir seu objetivo, o assassino clandestino que vaga especialmente à noite, algum homem mal que prejudica outros com seus feitiços; todos eles 'fazem kanaimé' como dizem os índios [...] (KOCH-GRÜMBERG apud CIRINO, 2009, p. 125).

Além da perspectiva de atribuir ao ataque de Kanaimé um artifício de vingança, a explicação está voltada a justificar que essa investida se respalda em uma condição que está além da simples vontade daquele que a pratica. A escolha, o planejar, a emboscada e o ataque muitas vezes não são aleatórios como alguns acreditam, sendo plausível que esse modo de agir possa ser impulsionado por forças mais poderosas do que a pessoa.

\footnotetext{
${ }^{6}$ Kanaimo, Kanaimés, Kanaimé, Kanaima, Canaima, Kanaimî, há formas diferentes de nomear este ser temido.
} 
Na Guiana, segundo Whitehead (2002), o Kanaimé também é visto como assassino feroz em narrativas recorrentes que se multiplicam largamente no imaginário cultural da população indígena. O universo sociocultural que caracteriza as práticas de Kanaimé apresenta elementos que postulam uma continuidade de caráter social entre humanos e não humanos. Whitehead (2002) ${ }^{7}$ aborda esse tema sob o ponto de vista de alguns trabalhos etnográficos sobre a violência cultural das práticas de Kanaimé. Segundo o autor os Kanaimé praticam uma mutilação de orifícios dos corpos de suas vítimas.

O Canaimé (Kanaimà) refere-se ao modo de mutilação, ritual que causa morte de vítimas. Pode significar uma ação espiritual maligna. O Canaimé opera em diversos níveis, podendo relacionar-se de forma dinâmica, ao mundo espiritual, as agressões físicas, as tensões e ciúmes entre aldeias e membros familiares. Os suspeitos são inimigos distantes e estão fora das aldeias. A etnografia do Kanaimî envolve ampla apreciação da vida cultural e social. Uma das características do Kanaimî é o fato de ser regional em suas práticas, mas não local. Ele é parte do repertorio cultural de grupos ameríndios, das montanhas da Guiana, que causa sofrimento a seus vizinhos próximos. Há casos históricos convincentes, rumores de selvageria, atribuições de responsabilidades, falsas acusações, fofocas sem base e acusações justificadas. $\mathrm{O}$ Kanaimî faz parte das conversas diárias desses povos, influência nas decisões do que as pessoas fazem, com suas visões de um cosmo cheio de deuses predadores e espíritos violentos e famintos de se saciarem com humanos. As decisões para ir à roça, viajar com alguém ou não, levar arma de fogo ou não, passar pela morada de um assassino famoso, ou caminhar a longas distâncias, desta forma é organizada a vida diária, influenciando seus aspectos práticos até suas concepções (WHITEHEAD, 2002, p.1).

As mortes por Kanaimé possuem algumas características. Na narrativa do Wapichana entrevistado, há referência à quebra do pescoço, enquanto Whitehead ouviu que o Kanaimé mutilava os orifícios nos corpos das vítimas.

A referência ao Kanaimé está atrelada tanto à prática, quanto aos seus praticantes, em um ritual com extenso significado físico para as vítimas. Essa violência carnal, primariamente de boca e ânus, rende à vítima não a morte propriamente, mas um processo lento de morte cuja ocorrência permite a formação da substância $m a b a^{8}$ dentro do corpo da vítima (CARVALHO, 2016, p. 64).

$\mathrm{O}$ artigo Canaimé de Roraima (Lenda ou realidade), postado na internet por Ivônio Solon Wapichana (2009), relata o que Ivônio diz ter ouvido dos antigos da sua comunidade. Nesse texto, ele conta o que acontecia com os Marynau que praticavam a maldade contra

\footnotetext{
${ }^{7}$ Neil Whitehead - Antropólogo inglês conhecido por seu trabalho sobre a antropologia da violência, xamanismo, Canaimé da Guiana e a antropologia histórica da América do Sul e do Caribe. Em Dark Shamans, Whitehead fala do lado pouco conhecido e mais obscuro do xamanismo, prática ainda observada entre os indígenas das terras altas da Guiana, Venezuela e Brasil, que envolve a perseguição ritual, mutilação, morte lenta, e consumo de vítimas humanas (CARVALHO, 2016).

${ }^{8}$ Maba é um líquido sugado do corpo em decomposição.
} 
outros parentes ${ }^{9}$. De acordo com a tradição Wapichana, segundo Ivônio, quando alguns pajés morriam, suas almas tornavam-se espíritos atormentados e ficavam vagando. Iam para as serras onde adormeciam dentro de uma planta que os antigos chamavam de tajá ${ }^{10}$. A essa planta são atribuídas tanto propriedades de cura, como de enfeitiçamento. Os pajés se utilizam dos poderes dessas plantas para ficar invisíveis, transformarem-se e tomar várias formas de animais. Mas, depois da colonização e catequização, este tema tornou-se delicado e nem todos os indígenas gostam de tratar.

Farage, em relação aos Wapichana divulgarem pouco acerca do tema, esclareceu que:

\begin{abstract}
A posse e uso de plantas mágicas não devem ser do conhecimento público; se interrogados diretamente, mulheres e homens negarão que possuam tais plantas. Além disso, sua posse e uso variam conforme o sexo: há usos específicos para homens e mulheres, e seu conhecimento é vedado de um sexo a outro, sobre pena de perderem a eficácia. Há ainda uma divisão entre o uso de indivíduos comuns - que os utilizam de forma laica, para garantir seu próprio sucesso, e o de seus cães, na caça, na pesca, na agricultura, no amor e tantos mais humanos projetos e interesses e xamãs, estes últimos possuindo não só um conhecimento de um espectro mais amplo de plantas, como fazendo delas um uso potenciado, o que faz com que alguns considerem que o xamã possui plantas mais poderosas. São obtidos frequentemente através de troca, onde figuram como item de extremo valor (FARAGE, 1997, p.74).
\end{abstract}

Algumas comunidades indígenas atribuem à utilização da pussanga, assim como de outras plantas, a capacidade de transformação em Kanaimé, face à propriedade de se transformar em animais com rabo, tais como cachorro, tamanduá, raposa, porco ou macaco.

Em algumas ocorrências narrativas o Kanaimé se escamoteia em pele de jaguar, assustando as vítimas que, desesperadas, adoecem e depois morrem. Seus ataques podem ocorrer por meio de maco -espécie de martelo de madeira - curto e grosso, que quebra os ossos da vítima e quando ela regressa à comunidade morre de febre em poucos dias (RABELO FILHO, 2012).

Na obra Literaturas da floresta, Lúcia Sá no capítulo "O sombrio coração das trevas" (2012, p.121), parte do romance Canaima, no qual Gallegos (1935) se vale de uma explicação indígena para definir o conceito caribe de Kanaimé:

O maligno, a divindade escura dos waikas e dos makiritares, o Deus exasperado, princípio do mal e causa de todos os problemas, disputa o mundo com Cajuña, a

\footnotetext{
${ }^{9}$ Ivônio chama de Marynau o que no texto acima nesse mesmo tópico nomeamos, de acordo com o que aprendemos com os Wapichana, chanaminayzu

${ }^{10}$ Tajá é uma planta muito comum na região amazônica. Também conhecida como tinhorão é uma planta bulbosa muito apreciada devido à sua folhagem ornamental. Ela apresenta folhas grandes, rajadas ou pintalgadas, com duas ou mais cores e tonalidades de branco, verde, rosa ou vermelho (CARVALHO, 2016, p. 16). É também conhecido na cultura indígena da região de Roraima como uma das plantas de onde se extrai substâncias para fazer pussanga. Pussanga é uma Medicação mágica receitada pelos pajés, após consulta aos espíritos, para curar doenças ou afastar malefícios (CARVALHO, 2016, p. 16).
} 
bondade. Demônio sem forma própria e capaz de assumir qualquer aparência, antigo Ahriman nascido na América (GALLEGOS apud SÁ, 2012, p. 127).

Há evidências, portanto, da presença do tema Kanaimé com outros nomes, sentidos entre diversos povos no Circum Roraima. Diversas observações são feitas a respeito do Kanaimé, dentre elas, eram mais comuns entre os indígenas as que reconhecem que ele ataca quando o Wapichana está sozinho, à noite, disfarçado de animal. Destaca-se ainda o fato de o Kanaimé tornar-se invisível através do uso de uma substância denominada djakoro. ${ }^{11}$

Uma característica marcante do universo Kanaimé é o fato de envolver uma combinação entre o ritual do modo de ação e um ataque. Tal como discute Neil Whitehead (2002), é impossível determinar a origem temporal do Kanaimé, pois o que se tem são relatos que remetem ao menos a duzentos anos de sua prática e interpretação, produzidos por fontes coloniais, textos antropológicos e literários.

A ação atribuída ao Kanaimé não é coisa do passado, mas uma realidade ainda presente nos dias atuais. $\mathrm{O}$ ataque do Kanaimé é certeiro e não há quem dele duvide. Isso é consequência da memória e credibilidade que os narradores das comunidades possuem e da forma como o Kanaimé tem sido reconstruído. ${ }^{12}$

Canaimé é o misto de pessoa, animal e espírito que ataca as pessoas de forma violenta. Como é chamada a figura espiritual e ao mesmo tempo física, que mata as pessoas sem chance de sobrevivência entre os indígenas da região. Há relatos de muitos indígenas que viram pessoas serem atacadas pelo Canaimé e não tiveram como sobreviver. Ele é causador de doença seguida de morte (ARAUJO, 2008, p. 33).

As referências escritas sobre Kanaimé aparecem nas fontes europeias a partir do século XIX, em um quadro de informações coloniais, como um modo de ação colocado em prática, em excursões de comércio e invasões predatórias pelos Akawaio, povo Caribe habitante da área de montanhas situadas na região ocidental da Guiana e que vive ao longo do rio Mazaruni e seus afluentes, fazendo vizinhança contra os Macuxi e os Patamona (CARVALHO, 2016, p. 39).

Conforme a proposta inicial do estudo, comparamos, ampliamos, dialogamos com o que ouvimos do nosso entrevistado e lemos de estudiosos que já pesquisaram a questão. $\mathrm{O}$ que no início olhamos sobre o ponto de vista de um Wapichana, terminou por evidenciar trocas culturais e negociações entre os Patamona, Akawaio, Macuxi, Wapichana e tantos

\footnotetext{
${ }^{11}$ Palavra Wapichana para indicar uma provável substância retirada de plantas.

12 O Kanaimé pode ser também, uma estratégia de resistência do povo contra a pressão homogeneizadora e assimilacionista que o Estado brasileiro praticou e pratica contra os povos indígenas, inferiorizando e apagando suas práticas socioculturais.
} 
outros povos citados aqui. São construções coletivas, multilíngues que ampliam nossas possibilidades literárias e de existência.

Após analisar algumas definições de Kanaimé, de conhecer suas práticas e os trabalhos do pajé, passaremos às narrativas de Михитихu sobre suas experiências com o Kanaimé e as histórias que ouviu de seus antepassados.

\title{
Narrativas de um Indígena Wapichana da Fronteira Brasil-Guiana
}

Assim, passamos agora ao texto que ouvimos do nosso entrevistado:

\begin{abstract}
Eu vim da comunidade Maruranau. Atravessei a fronteira para o Brasil, não vim porque queria, estávamos muito tristes. Nossos filhos morreram no mato. Nossa roça era grande, tinha muitas plantações, tinha feito minha roça tão grande, tinha muitas plantações: cana de açúcar, banana, cará, inhame e macaxeira. Era grande e bonita. Muitas pessoas tinham inveja. A verdade que atravessamos porque nossos dois filhos haviam sido mortos em uma semana, eu estava muito triste, naquele tempo os governantes não ligavam para o povo doente, sem jeep, sem remédio, estava muito difícil naquele tempo. E foi por isso que viemos para o Brasil encontrar algo melhor para gente. Não encontramos, não encontramos um bom trabalho aqui no Brasil, por isso que não temos todos documentos da Guiana, andávamos, trabalhávamos e não nos pagavam, mas eu posso dizer que estamos bem, já estou velho, estou vivendo aqui no Brasil há 25 anos. O meu trabalho é fazer tarrafa, desse jeito vou levando a vida. ${ }^{13}$
\end{abstract}

Com a finalidade de compreender a migração que envolve os povos Wapichana na fronteira entre os Estados Nacionais, faz-se necessário um breve estudo da construção da fronteira internacional entre o Brasil e a República Cooperativa da Guiana. De um lado, o Brasil, ex-colônia de Portugal e independente desde 1922, e de outro, a Guiana, ex-colônia holandesa e depois inglesa, até sua independência em 1966 (BAINES, 2004).

O deslocamento desses povos para o Brasil coincidiu ainda com o início do movimento político indígena da década de 1970 em Roraima, incentivado em grande medida pela Igreja Católica (BAINES, 2004). Antes da divisão de território entre Portugal e a

${ }_{13}$ Entrevista realizada com Muxumuxu no Bonfim dia 15/08/2017 traduzida para língua portuguesa. Na sequência está a transcrição do texto original da entrevista na língua Wapichana: unwa'atin Maruranau dikiu, na'apauran untaraykian karai wiiz at. Auna wa'atin wa, wanykyny kaxauran dii wazuwezun wadanha'u kanuk ii, ydary'u wazakapan, ydary’u,i ribi unpaurib na ii, kayweru, syyz, kirick, tipuy, wayni, irib Pidiannau dupian un at, napaidan kuxan. Kainha'a dirii wapauribei na'i, napadu'a mixiu kunaikiu, mazan na'apa xan. Irri wa wa'atin karai it wadainhau maukan diatan, baydap Sunday dia't, irri kaxauran unwanikinii dian it, xap nii ka'an idun aunaa nabanayinhau nikinipan pidian karian naii, aunaa jeeping, aunaa kasarai nai, dadara amazada idum, irri di wa watizun karai wiiz at, wadautiana watiana napain wakudan aimekan sud wa at, wazu kiani pua it radamat, mazan aunaa wakidezun, aunaa wakudan wakaydin kizei nii kaimenau karai wiiz it, xap naa ka'an aunaa wakarichinha nii diki ura, wachikipan aunaa wakuweitikau, atii karian, mazan kaimen unkian aizii, kayzii waynau, tynarynau ungary aizii, ikudana diay pidiannanaa bakai it wunun puau karai wiz at. Unkay kaydinkiz ungary so untumam sayru, iryy diany wakud wamaxapan maskaday. 
Inglaterra, formando assim a fronteira entre o Brasil e a Guiana, era tradicionalmente ocupado pelos povos Macuxi e Wapichana, o que justifica o fato dessa população viver nos dois lados da fronteira, transitando entre os dois países, muitas vezes, possuindo documentos de ambos e identificando-se como brasileiro ou guianense, conforme o país em que se encontram (BAINES, 2013).

$\mathrm{Na}$ atualidade, a fronteira entre a República Federativa do Brasil e a República Cooperativa da Guiana, foco da presente pesquisa, corresponde, no lado Brasileiro o município de Bonfim e no lado da Guiana a Lethen.

A partir da narrativa do entrevistado, discorremos aqui o que ele compartilhou sobre o motivo da sua vinda com a família para o Brasil. Começaremos a parir daqui a falar do sujeito Kanaimé e das concepções importantes sobre ele.

Por isso que eu vim do Maruranau, tem alguém que nos fez maldade, o Kanaimé, o Kanaimé matou os dois filhos meus. Ela disse antes de morrer: _ papai eu vou morrer, o Kanaimé me pegou. Eu não acreditei, ela morreu, passou uma semana outro filho morreu, o pescoço estava quebrado, verdade, tem Kanaimé, Kanaimé Wapichana, Kanaimé Macuxi também, todo lugar tem Kanaimé na Guiana, Brasil em todo lugar. ${ }^{14}$

A narrativa aborda o fato de duas mortes terem sido causadas pelo Kanaimé, por inveja ou outro motivo. O narrador considerou que foi por inveja, por ter grandes plantações, assim o Kanaimé acabou matando seus dois filhos.

Михитихи narrou ainda como surgiu e morreu o Kanaimé. Buscamos, a partir das referências estudadas, traçar um paralelo e identificar o que eles têm em comum. A partir de agora conheceremos a versão do entrevistado sobre como surgiu o Kanaimé:

Naquela época os Patamona eram os Kanaimé. Os Wapichana tinham medo dos
Patamona. Só alguns Wapichana que não. Eles vêm da Serra da Lua, sabem retornar
o feitiço para o outro. Os Patamona ${ }^{15}$ são perigosos, mais que os Wapichana. Eles
usam a planta poderosa, essa planta não é para matar gente não, mas para chamar
animais para caçar, mas não é sempre que as pessoas usam essa aí não. No sonho,
essa planta sempre fala com a pessoa que usa: _ eu não quero mais carne, quero
sangue agora. Meu sogro me contou que ele usava quando ia para o lavrado. Lá
sempre encontrava veado bem manso. Chegava perto e matava. Como sempre, trazia
o veado morto. Era essa planta que mostrava para ele. Isso aconteceu muitos anos,
mas às vezes as plantas voltam e dizem: - eu não quero animal mais não, eu quero
sangue de gente. Por isso o pessoal não planta aqui no seu quintal, porque tem
criança na casa, de noite as plantas ficam assobiando, quando era jovem eu tinha

\footnotetext{
${ }^{14}$ Entrevista realizada com Muxumuxu no Bonfim dia 15/08/2017. Tradução da transcrição da versão original na língua Wapichana: yryy watizun maranau ik, kainha wa atamintikeu idakutukau Kanaymy, Kanaymy zuan undainhau napain, xapana kaana ukaudan un at pumaukan na ii: _ Papa uumaukan aizii Kanaimy zamatan ungary. Aunaa unmixidian zamata ungary, mazan diatan kamuu diaytan, umaukazun, ii mixiran ukuadazun un at. Unkanay ramich, mixiu, ka'y Kanaymi wapichanau kainhaa, macuxinau kainhaa kuan, ipei kainhaa Kanaymi maxapan Guyana ii, karaii ii ipei amazad.

${ }^{15}$ Os Patamona também conhecidos como Ingarikó ou Kapon e fazem parte da família linguística Caribe. São um povo indígena que vive próximo aos Wapichana na Guiana.
} 
essa planta, plantei longe de casa, mas não usava para matar gente não, era mais para caçar animais. ${ }^{16}$

O entrevistado atribui o uso dessa planta para atrair caça, por possuir poderes de amansar os animais para depois o caçador abatê-los. Mas essa planta possui também poderes e necessidades que podem chegar a rejeitar a carne de animais e exigir a humana. Trata-se aqui da cosmovisão do entrevistado e de sua relação com a natureza, que não parece ser de superioridade, como acontece na lógica ocidental, em que o homem é um ser supremo, superior a todos os outros. Na narrativa, fica evidente que, na cosmovisão Wapichana, o ser humano estabelece uma relação simétrica com os outros seres (no caso em tela, as plantas), que têm vontade própria. A narrativa acima evidencia ainda a capacidade de alguns Wapichana se comunicarem com as plantas, ouvindo suas necessidades e ativando seus poderes. A origem do Kanaimé teria sido então o uso de uma planta antes com poderes de atrair caça, para "matar gente".

Outra narrativa de Мuхитихи, nosso entrevistado Wapichana conta sobre o medo de um povo contra o outro e de um Kanaimé que violentou muita gente em determinada comunidade:

\begin{abstract}
O meu tio Frank me contou essa história de uma tribo que estava com medo de outra tribo, mas dessa vez foram os Patamona. Eles estão longe, em Pacaraima por aí. Eles estão alegres, uma comunidade está alegre, foram no Sul de Rupununi. ${ }^{17}$ Eles sempre passavam por lá enganando as pessoas, comprando ralador ou flecha; mas não era só isso não. Isso acontecia antes do natal, natal naqueles dias tinha que ter muito cuidado, foi lá e pegou (matou) o homem importante da comunidade, o homem fazia as coisas da igreja, falava a palavra de Deus. Todo mundo ficou triste atrás do homem que morreu, mas na comunidade também tinha um homem, o Marynau que sabia retornar essas coisas (feitiços). Um homem, o Edward, falou para mim: _ele já está morto, para retornar essa coisa (feitiço) usam um peixe chamado Pudaii ${ }^{18}$. E chamou alguém da comunidade: o escolhido que tem coragem para se vingar e passou regra para realizar essa vingança. Um homem disse: _eu vou fazer. [...] Primeiro ele corta o dedo do corpo do morto e vai no mato bem distante sozinho, encontra um pé de açaí bem alto e comprido e faz curva no galho da palmeira e amarra esse no dedo do homem. Deixa aí por um mês e durante esse período ele deve ir no mato, o lugar onde está a palmeira sozinho rezar, jurar vingança para retornar para quem fez a maldade. Tem outras regras: não pode dormir com sua mulher, não ter sexo com mulher, não comer, tem que tomar só caldo de jiquitaia ${ }^{19}$ e água. O homem disse: _eu vou tentar, eu vou aguentar. Passou uma, duas semanas e terceira semana, sua mulher ficou muito triste ao ver o marido dela. Ele estava muito magro. A mulher dele disse: já é a terceira semana, o homem já está morto. Tu vais morrer atrás do homem também, vai lá e corta a corda, isso aqui, só eu e você vai saber_disse ela. [...] Ele foi e cortou a corda. Agora não sei onde vai cair o dedo, se vai cair para lá ou para cá, mas o pajé disse que: _tu vai ouvir uma coisa, onde o dedo cair vamos saber onde as pessoas estão
\end{abstract}

\footnotetext{
${ }^{16}$ Entrevista realizada com Михитихи, indígena Wapichana no Bonfim em 15/08/2017.

${ }^{17}$ Região 9, sul da Guyana (República Cooperativa da Guiana)

${ }^{18}$ Peixe pintado e pequeno e quando vê gente ele incha e fica grande.

${ }^{19}$ Pimenta seca e moída.
} 
morrendo. São eles que mataram, foi lá em Pacaraima, na serra, não sei onde, muitas pessoas alegres no natal, chegando o ano novo, todo mundo conhece todo mundo. Tem alguém doente na comunidade, vamos dar uma olhada, ele estava bem no natal. Agora passando mal, quando chegaram ele estava vivo ainda e depois morreu. Aí o mesmo homem que foi vê-lo, voltando para casa, no meio do caminho morreu. Todos que iam vendo os mortos iam morrendo. Não sei quantas pessoas morreram, uns quinze homens, não mulheres. Rapaz, depois a mulher sabia: _eu acho que foi os Wapichana, foi Wapichana mesmo. Ela acredita que os Wapichana são muito poderosos, mais do que os Patamona. Porque ninguém viu ninguém chegando aqui, ninguém viu, e os homens estão morrendo assim. Se aquele homem aguentasse mais um mês, toda comunidade ia morrer. Só os homens. Desde aí os Patamona respeitam os Wapichana. Mas, na verdade, os Wapichana não eram os Kanaimé não. Os Macuxi e Patamona sim, eles são. Mas agora tem Wapichana treinando para ser. Ele achou aquela planta, a planta leva a pessoa rapidinho. É só colocar na perna e sai voando, e depois tu volta, muito poderoso. ${ }^{20}$

Essa narrativa conta da morte de Kanaimé, uma prática poderosa realizada através dos conhecimentos do marynau. Na versão narrada o Kanaimé fez com que morressem apenas os homens. De fato, pelo que estudamos até o momento, a figura do Kanaimé nos pareceu ser masculina e ter também preferência por atacar homens. Já ouvimos histórias de mulheres que foram violentadas por Kanaimé, mas não morreram. Na narrativa acima, morreu praticamente uma comunidade inteira, mas para que isso viesse a ser concretizado, teve alguém indignado e a jurar vingança. E o marynau aceitou passar por procedimentos doloridos, tais como os descritos na entrevista citada acima: fez abstinência alimentar, apenas se alimentando de coisas específicas e abstinência sexual para conseguir estancar a onda de morte causada naquela localidade pelo Kanaimé.

O corpo de quem vira Kanaimé se sobrecarrega e a família que acompanha também sofre em silêncio. Chega a tal ponto, como consta a narrativa, que ele é obrigado a recuar por causa de suas limitações, o que faz com que o ritual não consiga atingir seu objetivo final que teria sido exterminar todos os homens daquele lugar. Mas mesmo tendo o pajé conseguido se preparar e matar o Kanaimé, o estrago foi grande e restou uma memória triste aos povos que foram atingidos.

Portanto, a ação atribuída ao Kanaimé não é coisa do passado, mas uma realidade ainda presente nos dias atuais. O ataque do Kanaimé é certeiro. É raro, entre os Wapichana, quem dele duvide. Ele permanece na memória desse e de outros povos indígenas em Roraima. E suas práticas têm sido perpetuadas e transmitidas pelas narrativas orais.

\section{Considerações finais}

\footnotetext{
${ }^{20}$ Entrevista realizada com o indígena Михитихи Wapichana no Bonfim em 15/08/2017.
} 
As narrativas indígenas aqui analisadas nos fizeram compreender a importância do Kanaimé na cultura Wapichana e como se processa esse fenômeno de violência física e simbólica (ataque de Kanaimé). O caminho aqui percorrido partiu das narrativas orais documentadas pela pesquisa de mestrado em andamento e nos levou a muitos registros sobre o tema, incluindo pensamentos de outros autores e povos indígenas.

O fenômeno da violência nas diversas sociedades difere-se de uma para outra. $\mathrm{O}$ Kanaimé pode parecer possuir uma especificidade muito cultural na vida dos povos indígenas Wapichana transfronteiriços, mas nos perguntamos: quem seriam os Kanaimé nas outras culturas? A violência é um fenômeno sócio-histórico que infelizmente jamais será extinto, visto que a sua onipresença está em todas as sociedades e culturas de que temos notícias.

Após terem sofrido a colonização e a catequização, alguns indígenas passaram a considerar a pajelança, tal como a violência do Kanaimé, uma fonte permanente de perigo e ameaça. Isso aconteceu também sob o ponto de vista dos próprios invasores que sentiram medo do Kanaimé e do poder dos pajés. A visão demonológica do outro, principalmente após a inserção o do cristianismo entre os indígenas Wapichana, apresenta tradição de preconceito, considerando as narrativas de Kanaimé nada além de superstição e primitivismo. Consideramos que o Kanaimé não é o demônio, é apenas uma ameaça, uma representação da maldade.

Assim, cabe reforçar a importância social das narrativas orais em uma comunidade, a exemplo dos textos de Kanaimé que rompem barreiras e atravessam fronteiras. E mesmo com a entrada do cristianismo, de toda gama de informação e comunicação entre as comunidades indígenas, a figura do Kanaimé continua viva e alimentando a construção da identidade Wapichana.

A forma como o indígena Wapichana Михитихи por nós entrevistado narrou as histórias contadas pelo seu tio, com uma oralidade multilíngue compreensível e fluência na performance narrativa, fez com que conseguíssemos ligar o passado ao presente em uma relação dialógica que tenta perpetuar histórias através da oralidade. A voz e a performance do narrador conduziram a nossa imaginação para um mundo que inclui o Kanaimé e o trabalho do pajé. A beleza e complexidade de suas narrativas nos levaram ao que uma história bem contada tem.

\section{REFERÊNCIAS}

ALBERTI, Verena. Manual de História Oral. 2. ed. FGV. Rio de Janeiro: 2004. 
. História Oral: a experiência do CPDOC. FGV. Rio de Janeiro: 1989.

AMADO, Janaina; FERREIRA, Marieta de Moraes (orgs). Usos e Abusos da História Oral. $8^{\text {a }}$ Ed. Rio de Janeiro: Editora FGV, 2006.

ARAUJO, Melvina. Misiones religiosas y politicas identitárias: las missiones de los Consolatinos en Kenya y Roraima. Memória Americana 16 (1), 2008.

BAINES, Stephen Grant. A fronteira Brasil-Guiana e os povos indígenas. In: Revista de Estudos e Pesquisas, FUNAI, Brasília, v.1, n.1, p.65-98, jul. 2004.

Povos indígenas na fronteira Brasil-Guiana e os megaprojetos de integração econômica. In: Cienc. Cult., São Paulo, v.65 n.1, jan. p. 40-42, 2013.

BENJAMIN, Walter. 1892-1940 O narrador. In: Magia e Técnica, arte e política. Ensaios sobre Literatura e histórias da cultura. Obras escolhidas, v.1. São Paulo: Brasiliense, 1994.

CARVALHO, Agnaldo Teixeira de. Canaimé, a personificação do mal. Dissertação (Mestrado em Letras) Universidade Federal de Roraima, Roraima, 2016.

CIRINO, Carlos Alberto Marinho. A "boa nova" na língua indígena: contornos da evangelização dos Wapishana no século XX - Boa Vista: Editora da UFRR, 2008.

FARAGE, Nádia. As Flores da Fala: práticas retóricas entre os wapishana. Programa de PósGraduação em Letras. São Paulo: 1997.

FRASER, Ronald. História Oral, História Social. História social, n¹7, p. 131-139 outono 1993.

IBGE. Instituto Brasileiro de Geografia e Estatística. Censo 2010. Disponível em $<$ https://www.google.com.br/?client=safari\&channel=iphone_bm> acesso em 12/01/2020.

ISA. Povos Indígenas do Brasil: Quem são? Última modificação em 14 de março de 2018. (Categoria Demografia). Disponível em:

$<$ https://pib.socioambiental.org/pt/Quantos_são\%3F>.Acesso em: 20/04/2018. 
KOCH-GRÜMBERG, Theodor. Del Roraima al Orinoco (1911-1913). Tomos I, II, III. Caracas: Ediciones del Banco Central de Venezuela, [1924] 1984.

LIMA, Lucas Pereira das Neves Souza. Ilhados: estratégias e feições territoriais Wapichana na Terra Indígena Manoá-Pium. 2013. 155 f., il. Dissertação (Mestrado em Sociologia) Universidade de Brasília, Brasília, 2013.

MUNDURUKU, Daniel. Em busca de uma ancestralidade brasileira. Revista Fazendo Escola, Alvorada, v. 2, 2002.

RABELO FILHO, Manoel Gomes. A representação social do Kanaimî, do Piya'san e do Tarenpokon nas malocas Cantagalo e Maturuca. Dissertação de Mestrado em Ciências da Religião. Universidade Católica de Pernambuco. Recife: 2012.

RODRIGUES, Aryon Dall'Igna. Linguas Brasileiras: para o conhecimento das línguas indígenas. $2^{a}$ edição. São Paulo: E. Loyola, 1994.

SÁ, Lucia. Literaturas da floresta: Textos amazônicos e cultura latino-americana. Rio de Janeiro: EDUERJ, 2012.

SHOMBORGK, R.H. Travels in Guiana and on the Orinoco during the years 1835-1839. Georgetoown: The Argasy Company, 1931.

WAPICHANA, Ivonio Solon. Canaimé de Roraima (Lenda ou realidade), 2009. Disponível em < https://www.indiosonline.net/canaime-de-roraima-lenda-ou-realidade/> acesso em $24 / 05 / 2020$.

WHITEHEARD, Neil. Dark Shamans- Kanaima and the Poetocs of Violent Death. Duke University Press: Durham\&London, 2002.

Recebido em 24/05/2020. Aceito em 13/07/2020. 